\title{
Numerical Analysis of Indoor Sound Quality Evaluation Using Finite Element Method
}

\author{
Yu-Tuan Chou ${ }^{1}$ and Shao-Yi Hsia ${ }^{2}$ \\ ${ }^{1}$ Department of Applied Geoinformatics, Chia Nan University of Pharmacy \& Science, Tainan 717, Taiwan \\ ${ }^{2}$ Department of Mechanical and Automation Engineering, Kao Yuan University, Kaohsiung 821, Taiwan \\ Correspondence should be addressed to Shao-Yi Hsia; syhsia@cc.kyu.edu.tw
}

Received 30 September 2013; Accepted 2 November 2013

Academic Editor: Teen-Hang Meen

Copyright ( 2013 Y.-T. Chou and S.-Y. Hsia. This is an open access article distributed under the Creative Commons Attribution License, which permits unrestricted use, distribution, and reproduction in any medium, provided the original work is properly cited.

\begin{abstract}
Indoors sound field distribution is important to Room Acoustics, but the field suffers numerous problems, for example, multipath propagation and scattering owing to sound absorption by furniture and other aspects of décor. Generally, an ideal interior space must have a sound field with clear quality. This provides both the speaker and the listener with a pleasant conversational environment. This investigation uses the Finite Element Method to assess the acoustic distribution based on the indoor space and chamber volume. In this situation, a fixed sound source at different frequencies is used to simulate the acoustic characteristics of the indoor space. This method considers the furniture and decoration sound absorbing material and thus different sound absorption coefficients and configurations. The preliminary numerical simulation provides a method that can forecast the distribution of sound in an indoor room in complex situations. Consequently, it is possible to arrange interior furnishings and appliances to optimize acoustic distribution and environmental friendliness. Additionally, the analytical results can also be used to calculate the Reverberation Time and speech intelligibility for specified indoor space.
\end{abstract}

\section{Introduction}

Economic development in human society has been more demanding in terms of quality of life, particularly in relation to noise issues. Noise is defined as undesirable sound or sound with inappropriate timing and location. Noise thus includes sound that interferes with talking and listening and may include sound with a potential to damage hearing. In modern living environments, noise is ubiquitous and includes pile driving and hammering on construction sites, vehicle engines and horns, and mechanical sounds associated with printing, underground factories, or other industrial activities. Noise quality of vehicles and electric appliances causes stress, and noise problems associated with public construction, which can affect a citizen's health and damage quality of life, are also emphasized. This makes it necessary to understand noise characteristics and then select a favorable engineering control to protect people against noise. Current domestic research on the evaluation of interior sound fields rarely considers the evaluation of environmental noise, and distinct approaches are applied to test and evaluate different noise sources. Noise evaluation indices and sound field simulation are commonly employed for interior sound field analyses. In a residential study, Huang and Lai [1] measured existing noise environments, including volume and location analyses of various noise sources, and found that the allowance for interior noise ranged between $30 \mathrm{~dB}(\mathrm{~A})$ and $40 \mathrm{~dB}(\mathrm{~A})$ in foreign countries. Hsieh [2] discussed real cases involving air-conditioning noise in auditoriums in Taiwan and discovered that most did not conform to permit standards for background noise. The main problem was that air conditioners were excessively noisy when activated and $14 \mathrm{~dB}(\mathrm{~A})$ higher than when switched off. Hsieh et al. [3] discussed the present situation of background noise in cultural centers and the objective measurement of background noise, specifically air-conditioning in the main building. The results demonstrated that air conditioners were the major background noise source in $95 \%$ of cases. Chen and Chung [4] introduced the acoustic characteristics of a newly built studio, including the design and measurement results of 
Reverberation Time, air soundproofing, and floor sound insulation, and discussed the design feasibility. Chiang et al. [5] analyzed the impulse responses measured in three theater types using Hyper Signal to measure the physical parameters of acoustic competence and compared how enclosure affected that acoustic competence. Chang et al. [6] used the jury testing to establish an evaluation procedure for human hearing perception in indoor space. They carried out this testing in three types of residential spaces and built a reasonable sound quality assessment method. Vorlander [7] reviewed the concept and implementations of room simulation methods. He found that a better prediction of Reverberation Times can be derived by using the theory of error propagation of uncertainties.

Among various methods used in discussions of simulation, the Finite Element Method is commonly utilized in research analyses. It tends to obtain solutions by simplifying complex problems, such as those involving complex and irregular boundary conditions and loads. Huang and Yang [8] developed a prediction model to calculate the sound pressure level in a small space. The FEM is employed to solve the indoor sound field and obtain good quantitative sound characteristics at low frequency. Aretz and Vorlander $[9,10]$ presented series of papers on the realistic simulation of car audio sound in car passenger compartments using a combined Finite Element (FE) and Geometrical Acoustics (GA) approach. The simulations are conducted for the whole audible frequency range with the loudspeakers of the car audio system as the sound sources. Their study clearly points out the strengths and weaknesses of the applied methods depending on the considered frequency range and material characteristics.

This study analyzes the characteristics of interior sound fields with fixed capacity and sound sources. The effects of shape, absorption property, and room boundary on sound delivery are analyzed to determine the improvement of interior noise. The research results can be used in the predesign of interior architecture to improve interior noise, decrease construction costs, and improve living quality.

\section{Basic Theory}

2.1. Basic Theory of Interior Sound. Sound comprises pressure change that resulted from the vibration of objects or molecules (the sound source), which, transmitted through water, air, or other media (communication path), becomes mechanical energy detected by human ears (the sound body). The waveform of sound comprises the mathematical and physical characteristics of sine waves, including frequency, wavelength, time lapse, and phase angle. Sound volume is normally represented using the physical quantity of sound pressure, with the unit of measurement being decibels $(\mathrm{dB})$, and is related to an object's vibration. Volume is the subjective perception of human ears of the amplitude, which differs from the definition in physics.

The sound discrimination ability of human ears exhibits nonlinear characteristics and is sensitive to distinct frequency. The general auditory frequency of human ears appears at $20-20 \mathrm{kHz}$. Sound pressure and sound intensity are normally used to measure sound as the perception of loudness changes with frequency. In this case, noise level meters are generally equipped with different weighted noise levels, A, B, and C, where weighted noise level A most closely resembles the human ear.

W. C. Sabine spent five years seeking to improve acoustics in university lecture halls and developed the famous Reverberation Theory, which defined Reverberation Time (RT) to present reflection time for a direct sound to decay $60 \mathrm{~dB}$. He further explained the relations between the shape, size, and decoration of a room, which could improve the quality of interior listening environment, as well as Reverberation Time, which became the determinant of Room Acoustics [11]. After the production of an indoor sound source, the interior sound field achieved the static state and then constantly reflected sound when the sound source was stopped to prevent immediate disappearance of the sound. The situation whereof the sound did not immediately disappear was called Reverberation, and the period for which it persisted was called the Reverberation Time. Reverberation Time in the design of Room Acoustics is generally known as Regulated Reverberation Time, which is defined as the time required for stable sound pressure attenuating $60 \mathrm{~dB}, T_{60}$ (or reducing the sound energy density down to the millionth static sound energy density). Clarity refers to the ability of the audience to clearly discriminate the parts and notes (music) and accurately hear the syllables (language) when the sound (language or music) is transmitted to them. Clearness and reverberation are two aspects of a single phenomenon and are inversely related to each other. Consider

$$
T_{60}=\frac{0.049 \mathrm{~V}}{-S \ln (1-a)},
$$

where $T_{60}$ is the Reverberation Time (sec), $V$ is the room capacity (cubic feet), $a$ is the average room surface absorption coefficient, and $S$ is the total room reflection surface (square feet).

Three sound waves are transmitted in interior sound environments. Direct sound indicates that the sound source is directly transmitted to the receiving point without influence from interior interfaces $[11,12]$. Reflected sound describes the reflected sound in circumstances where the time delay is less than 50 ms. Reverberant sound describes the situation where sound is constantly reflected, where length and attenuation are considered the key factors in Room Acoustic design.

When analyzing indoor acoustic simulation, the coupling of fluid and a structure is generally taken into account [13]. Meanwhile, the dynamic equation for a structure and NavierStokes equation for flow are also calculated and analyzed. Assuming fluid being compressible and nonviscous, average velocity being zero, and average pressure and density being uniform, the continuous equations could be simplified as an acoustic wave equation in the kinematic equation for fluid. Consider

$$
\frac{1}{c^{2}} \frac{\partial^{2} P}{\delta t^{2}}-\nabla^{2} P=0
$$


where $c$ is the velocity of sound of fluid, $P$ is the the acoustic pressure, and $t$ is the time. In consideration of the harmonic change of acoustic pressure with frequency, it is assumed that

$$
P=\bar{P} e^{j \omega t}
$$

where $\bar{P}$ stands for the amplitude of acoustic pressure and $\omega$ is the frequency. Equation (2) could be simplified as Helmholtz equation as follows:

$$
\frac{\omega^{2}}{c^{2}} \bar{P}+\nabla^{2} \bar{P}=0
$$

Since the spillover effect of viscous energy of fluid is ignored, the lossless wave equation could be proceeded spatial discretization when combining with the structure dynamic equation. The original differential operator $\nabla$ could be transformed into the matrix operator as follows:

$$
\nabla \cdot(\quad)=\{L\}^{T}=\left[\begin{array}{lll}
\frac{\partial}{\partial x} & \frac{\partial}{\partial y} & \frac{\partial}{\partial z}
\end{array}\right]
$$

2.2. Applying Finite Element Method to Sound Field Analysis. This study establishes the Finite Element Method as the model used for interior sound field analysis. With the development of CAE during recent decades, the Finite Element Method (FEM), Boundary Element Method (BEM), and Finite Differential Method (FDM) have been developed for different applications. Finite Element Analysis (FEA), being widely utilized, was based on Hamilton's Variation Principle, which was defined as the total energy required to achieve extreme values in neighboring areas. Based on this definition, analyses can be performed to calculate the sum energy, and the Euler-Lagrange differential equation can be derived using differential calculus. The governing equation is a simultaneous multivariate partial differential equation where an accurate solution can be obtained by given simple shape, boundary condition, and material property of the domain. Nevertheless, this approach only yields approximate solutions when applied in the real world.

Finite Element Method is composed of nodes and elements and replaces the original engineering systems. Additionally, a complete FEM contains the boundary conditions of constraints and external loads of an engineering system. This study uses ANSYS to simulate the sound field distribution under fixed noise sources in an interior space, where sound sources can be indoor fan or air-conditioner noise, and the floor, surroundings, and air can be the media that consider the absorption characteristics. The simulation results can be used to clarify the changes in sound field characteristics, such as frequency, location, and intensity of sound sources in distinct interior space and boundary reflections.

The strong form governing equation will be converted to weak form for obtaining the discrete algebraic equation. Multiplying (2) by a virtual change in pressure $\delta P$, the differential form is transformed into a ranged volume integral using Galerkin method as follows:

$$
\begin{gathered}
\int_{\mathrm{vol}} \frac{1}{c^{2}} \delta P \frac{\partial^{2} P}{\partial t^{2}} d(\mathrm{vol})+\int_{\mathrm{vol}}\left(\{L\}^{T} \delta P\right)(\{L\} P) d(\mathrm{vol}) \\
=\int_{S}\{n\}^{T} \delta P(\{L\} P) d(S)
\end{gathered}
$$

where vol is the volume of the scope of analysis, $S$ is the curve of the coverage, $\{n\}$ is the positive vector of the curve, and the curve $S$ is the interface in the coupling of fluid structures. In the simplification assumption, the momentum equation of fluid forms a pressure gradient on the surface of the structure, resulting in a positive acceleration on the surface. The relations appear as

$$
\{n\}^{T}(\{L\} P)=-\rho_{0}\{n\}^{T} \cdot \frac{\partial^{2}\{u\}}{\partial t^{2}},
$$

where $\{u\}$ is the displacement vector of the structure on the interface and $\rho_{0}$ is the fluid density. Substituting (6) into (5), it shows

$$
\begin{gathered}
\int_{\mathrm{vol}} \frac{1}{c^{2}} \delta P \frac{\partial^{2} P}{\partial t^{2}} d(\mathrm{vol})+\int_{\mathrm{vol}}\left(\{L\}^{T} \delta P\right)(\{L\} P) d(\mathrm{vol}) \\
=-\int_{S} \rho_{0} \delta P\{n\}^{T} \frac{\partial^{2}\{u\}}{\partial t^{2}} d(S) .
\end{gathered}
$$

In the solution process with Finite Element Method, the physical quantity of the points in the scope of analysis could be approximated with the following shape functions for the elements. Consider

$$
\begin{gathered}
P=\{N\}^{T}\left\{P_{e}\right\}, \\
u=\left\{N^{\prime}\right\}^{T}\left\{u_{e}\right\},
\end{gathered}
$$

where $(N)$ is the shape function of pressure, $\left\{N^{\prime}\right\}$ is the shape function of displacement, $\left\{P_{e}\right\}$ is the pressure vector of a node, and $\left\{u_{e}\right\}=\left\{u_{x e}\right\},\left\{u_{y e}\right\},\left\{u_{z e}\right\}$ is the composition of vector of node displacement. The differential shape function with the differential operator $\{L\}$ is shown as

$$
[B]=\{L\}\{N\}^{T} \text {. }
$$

Substituting it with (8), the following equation is acquired:

$$
\begin{gathered}
\frac{1}{c^{2}} \int_{\mathrm{vol}}\{N\}\{N\}^{T} d(\mathrm{vol})\left\{\ddot{P}_{e}\right\}+\int_{\mathrm{vol}}[B]^{T}[B] d(\mathrm{vol})\left\{P_{e}\right\} \\
+\rho_{0} \int_{S}\{N\}\{n\}^{T}\left\{N^{\prime}\right\}^{T} d(S)\left\{\ddot{u}_{e}\right\}=\{0\} .
\end{gathered}
$$

Equation (11) could be simplified as

$$
\left[M_{e}^{P}\right]\left\{\ddot{P}_{e}\right\}+\left[K_{e}^{P}\right]\left\{P_{e}\right\}+\rho_{0}\left[R_{e}\right]^{T}\left\{\ddot{u}_{e}\right\}=\{0\},
$$

where $\left[M_{e}^{P}\right]=\left(1 / c^{2}\right) \int_{\mathrm{vol}}\{N\}\{N\}^{T} d(\mathrm{vol})$ is the fluid mass matrix, $\left[K_{e}^{P}\right]=\int_{\mathrm{vol}}[B]^{T}[B] d(\mathrm{vol})$ is the fluid stiffness matrix, $\rho_{0}\left[R_{e}\right]=\rho_{0} \int_{S}\{N\}\{n\}^{T}\left\{N^{\prime}\right\}^{T} d(S)$ is the coupling mass matrix. 


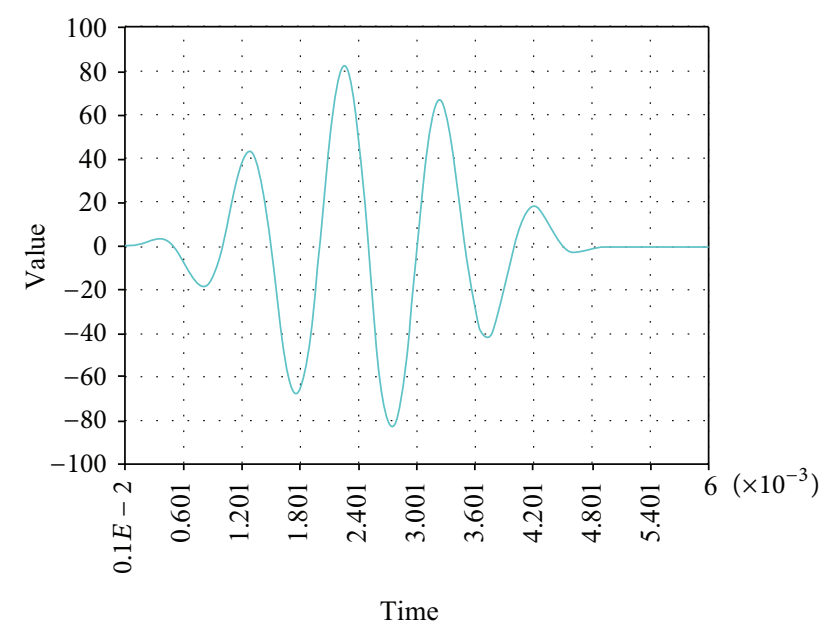

FIGURE 1: Delivery of pulse sound pressure at the $0.001 \mathrm{sec}$.

Equation (12) presents the wave equation of fluid, and the dynamic equation of a structure is shown as

$$
\left[M_{e}\right]\left\{\ddot{u}_{e}\right\}+\left[C_{e}\right]\left\{\dot{u}_{e}\right\}+\left[K_{e}^{P}\right]\left\{u_{e}\right\}=\left\{F_{e}\right\}+\left\{F_{e}^{\mathrm{pr}}\right\},
$$

where $\left\{F_{e}^{\text {pr }}\right\}$ is the pressure load of fluid, which, with pressure integrals, is shown as below. Consider

$$
\begin{aligned}
\left\{F_{e}^{\mathrm{pr}}\right\} & =\int_{S}\left\{N^{\prime}\right\} P\{n\} d(S) \\
& =\int_{S}\left\{N^{\prime}\right\}\{N\}^{T}\{n\} d(S)\left\{P_{e}\right\}=\left[R_{e}\right]\left\{P_{e}\right\} .
\end{aligned}
$$

Equations (12) to (14) could be organized as

$$
\begin{gathered}
{\left[\begin{array}{cc}
{\left[M_{e}\right]} & {[0]} \\
{\left[M^{f s}\right]} & {\left[M_{e}^{P}\right]}
\end{array}\right]\left\{\begin{array}{l}
\left\{\ddot{u}_{e}\right\} \\
\left\{\ddot{P}_{e}\right\}
\end{array}\right\}+\left[\begin{array}{cc}
{\left[C_{e}\right]} & {[0]} \\
{[0]} & {\left[C_{e}^{P}\right]}
\end{array}\right]\left\{\begin{array}{l}
\left\{\dot{u}_{e}\right\} \\
\left\{\dot{P}_{e}\right\}
\end{array}\right\}} \\
+\left[\begin{array}{cc}
{\left[K_{e}\right]} & {\left[K^{f s}\right]} \\
{[0]} & {\left[K_{e}^{P}\right]}
\end{array}\right]\left\{\begin{array}{l}
\left\{u_{e}\right\} \\
\left\{P_{e}\right\}
\end{array}\right\}=\left\{\begin{array}{c}
\left\{F_{e}\right\} \\
\{0\}
\end{array}\right\},
\end{gathered}
$$

where $\left[M^{f s}\right]=\rho_{0}\left[R_{e}\right],\left[K^{f s}\right]=-\left[R_{e}\right]$.

The internal approximate values of the elements could be calculated with (15). The matrix equation of the scope of analysis could be acquired by integrating all elements for further calculating the pressure and displacement.

\section{Implementation and Procedure}

Working environment is the main influence on human productivity and health that improves interior environments to reduce personnel costs through simulations that minimize loss. The Finite Element Method transforms the engineering system into the Finite Element System for the simulation and analyses. Among the acoustic parameters, the absorption coefficient is one of the main factors and is used to quantify the absorption competence for the reference and the application of soundproofing engineers interested in calculating attenuated volume. The absorption coefficient is

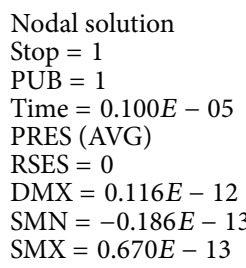

\begin{tabular}{|c|c|c|c|c|c|c|c|c|}
\hline C & $\Xi$ & 120 & \pm & 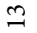 & $\stackrel{?}{\sim}$ & 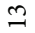 & 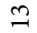 & 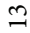 \\
\hline & 1 & 1 & I & 1 & 1 & 1 & 1 & 1 \\
\hline & [II & II & II & II & 닌 & 기 & II & {$[1]$} \\
\hline & ํㅇㅇ & 윰 & ลे & $\stackrel{2}{=}$ & ণิ & $\begin{array}{l}n \\
\infty \\
m \\
\end{array}$ & 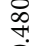 & $\stackrel{n}{\stackrel{n}{n}}$ \\
\hline & $\dot{0}$ & i & i & $\dot{\varphi}$ & $\dot{0}$ & i & $\ddot{i}$ & i \\
\hline
\end{tabular}

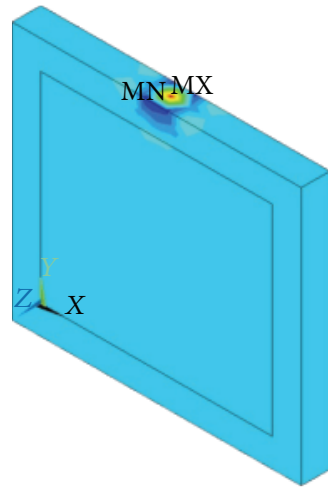

FIgURE 2: Stereo diagram of sound field before the diffusion at $1 \times$ $10^{-6} \mathrm{sec}$.

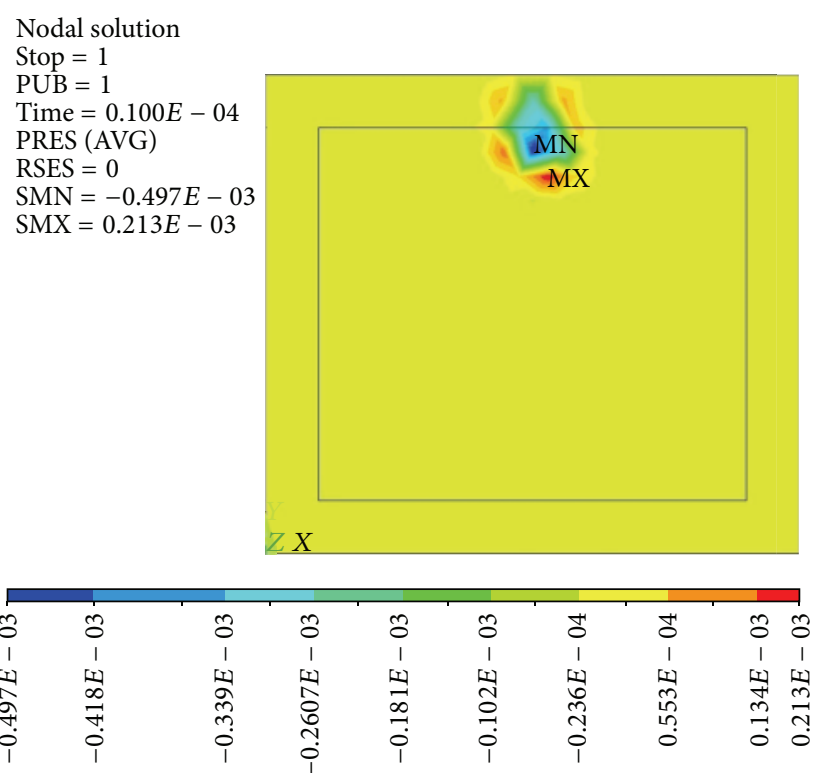

FIgURE 3: Sound field distribution after $1 \times 10^{-5} \mathrm{sec}$.

the competence indicator of absorption materials. When the sound is transmitted to absorption materials, the sound is partially reflected and partially absorbed, as the commonly used porous absorption materials present a loose structure that allows easy sound penetration. Furthermore, absorption materials are generally fitted on thick structures like walls and metal plates that sound does not easily penetrate but from which is easily reflected. Small $E_{t}$ often ignores that the absorption coefficient is simplified as $a=E_{a} / E_{i}$. Furthermore, the absorption coefficient ranges from 0.0 to 1.0, where higher value indicates the material has better absorption. In contrast, materials with worse absorption are reflective, where $a=1.0$ presents complete absorption and 


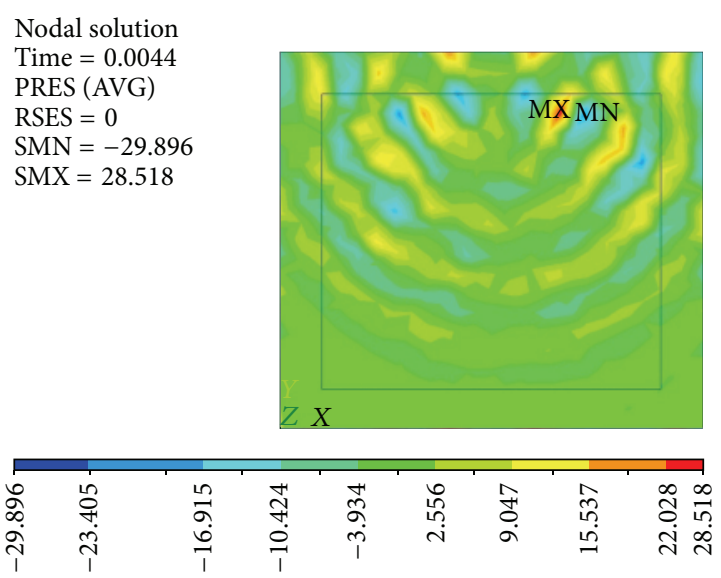

FIGURE 4: Boundary reflection with the delivery time $0.0044 \mathrm{sec}$.
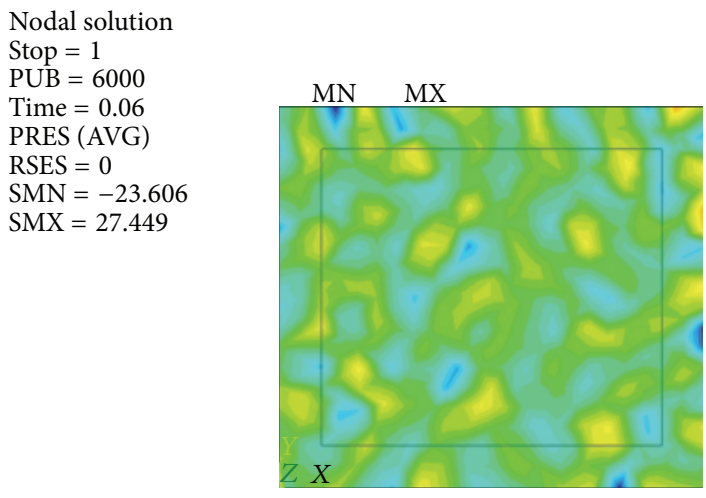

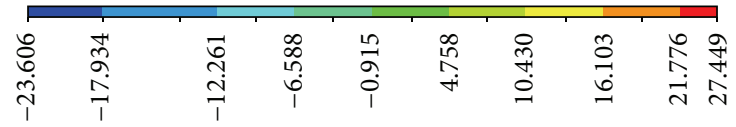

FIgURE 5: Stable state of sound pressure after several reflections.

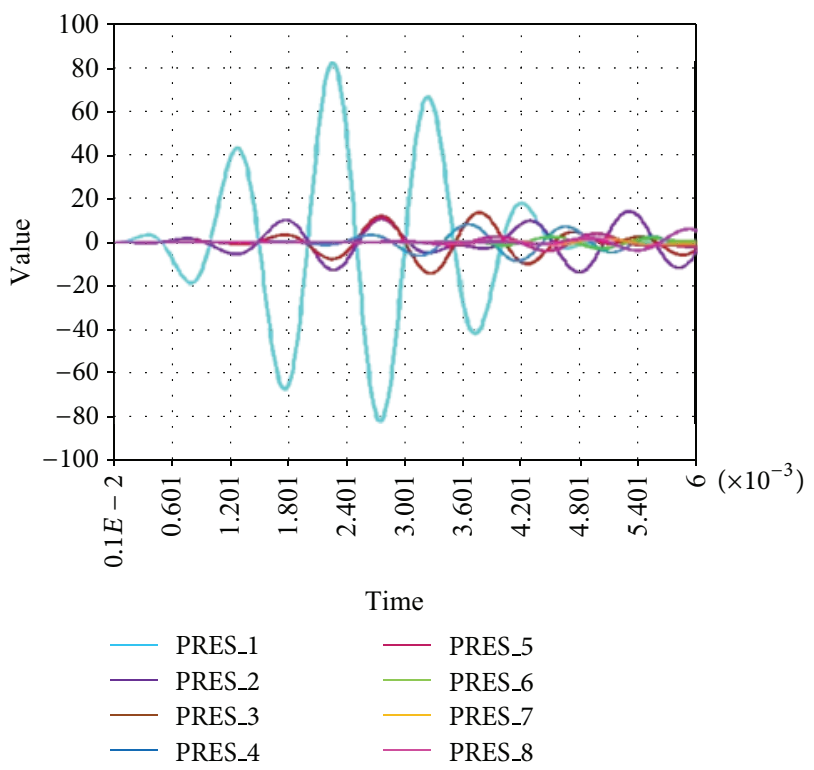

Figure 6: Sound decay phenomena along the perpendicular direction of the sound source.

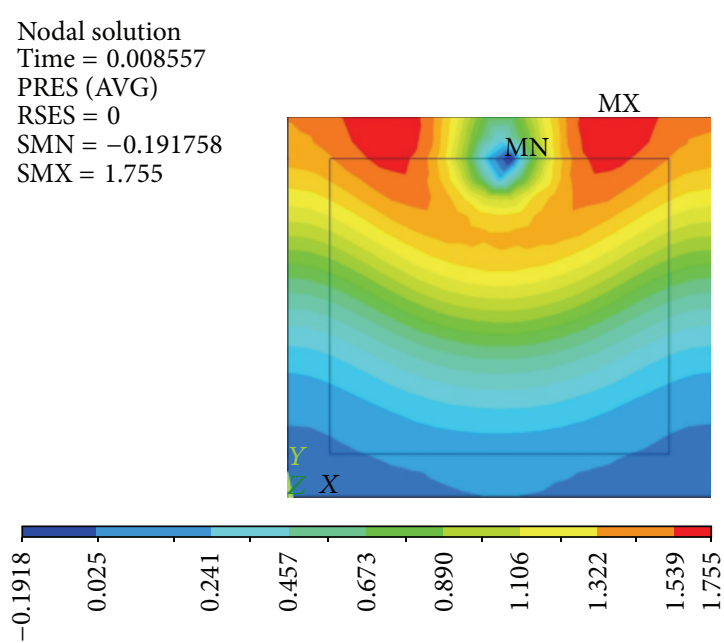

FIGURE 7: Sound pressure distribution of the fan noise for propagating to the ground.

TABLE 1: Input parameters for this research analysis.

\begin{tabular}{lcc}
\hline Properties & Air & Wall \\
\hline Length $(\mathrm{m})$ & 2.13 & 2.74 \\
Width $(\mathrm{m})$ & 0.31 & 0.31 \\
Height $(\mathrm{m})$ & 2.44 & 3.05 \\
Density $\left(\mathrm{kg} / \mathrm{m}^{3}\right)$ & 1.29 & 2600 \\
Velocity $(\mathrm{m} / \mathrm{sec})$ & 335.28 & 3100 \\
Absorption coefficient & $\sim 0 .$. & $0.04-0.70$ \\
\hline
\end{tabular}

$a=0.0$ indicates complete reflection. Nonetheless, complex sound diffusion exists in the interior sound field, such as the interior surface and in the reflection of objects, such that changes of interior sound field are difficult to estimate.

Finite Element Analysis precedes the simulation in the environment with existing room arrangement, room capacity, and fixed sound sources and discusses the effects of room boundary on Reverberation Time of interior language under distinct frequency. In the analysis, the room shape and materials influence the reflection, diffraction, and scattering of sound and allow organization of the transmission in the space and the acquisition of interior data such as room size and absorption materials used on walls. The software is utilized to obtain the sound pressure distribution and Reverberation Time indoors. The results can be compared with the measured value of interior sound pressure to improve interior noise. The research results can also be used in preanalyses to improve the interior noise. Such measures not only can effectively reduce construction costs, but also can improve living quality. Table 1 lists the input parameters used in the present research analysis.

\section{Simulation Results and Discussion}

Finite Element Analysis is applied to analyze the interior sound field with fixed capacity and sound sources. The effects of room shape, absorption characteristics, and boundary are 


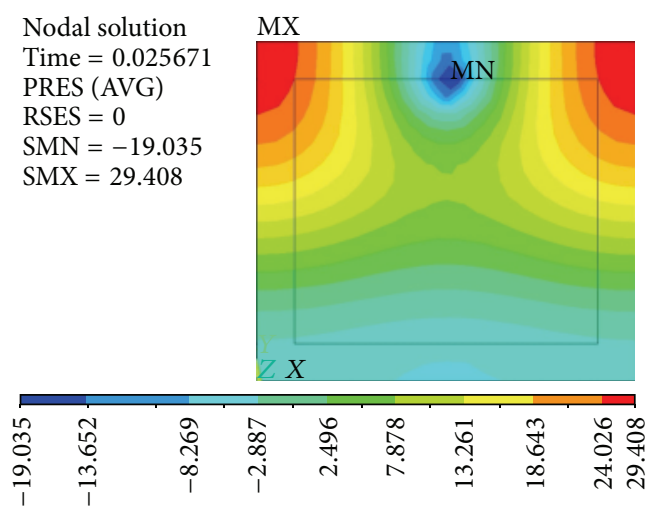

(a) $63 \mathrm{~Hz}$

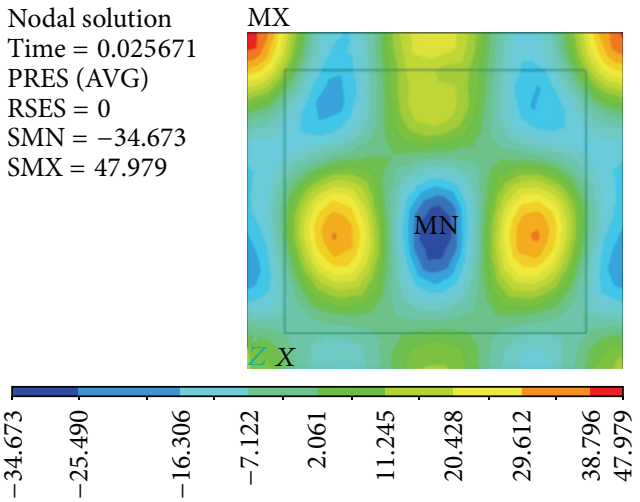

(c) $250 \mathrm{~Hz}$

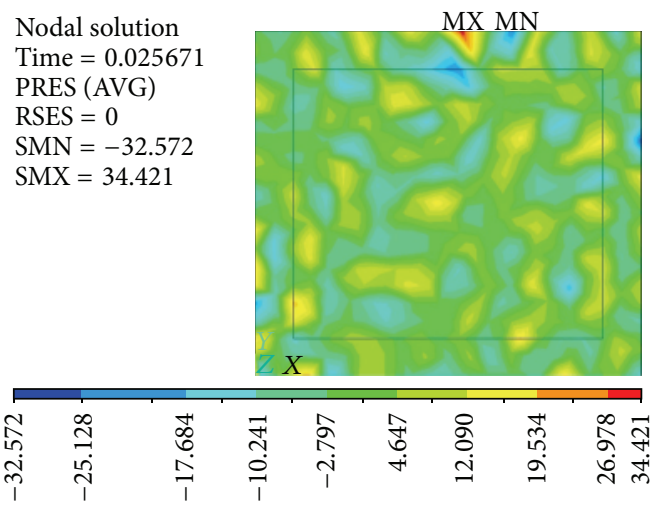

(e) $1000 \mathrm{~Hz}$

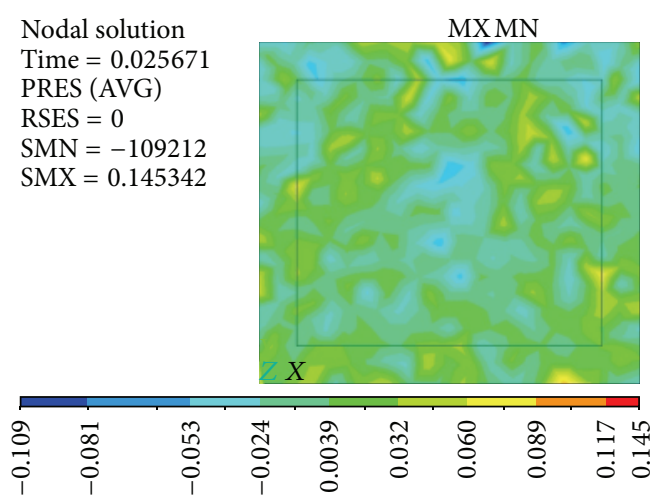

(g) $4000 \mathrm{~Hz}$

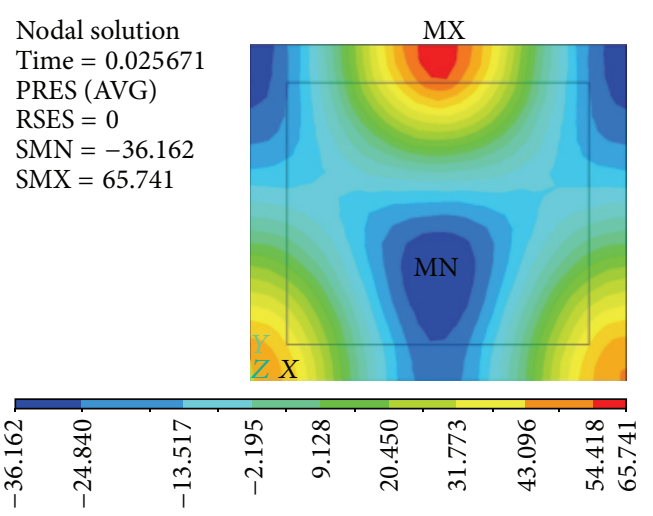

(b) $125 \mathrm{~Hz}$

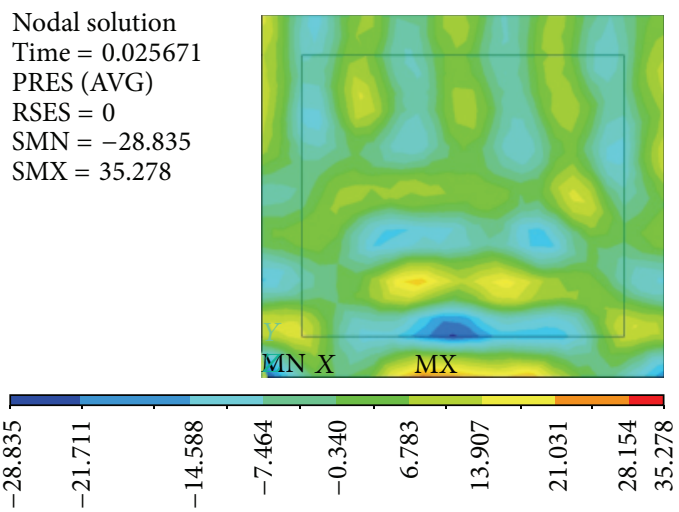

(d) $500 \mathrm{~Hz}$

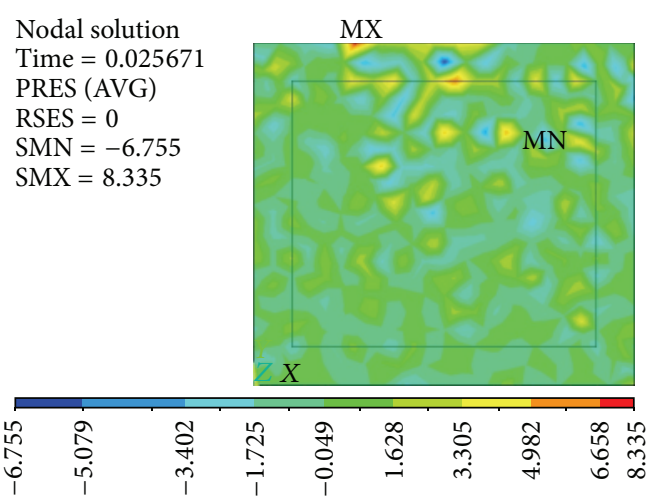

(f) $2000 \mathrm{~Hz}$

Nodal solution Time $=0.025671$ PRES (AVG)

RSES $=0$

SMN $=-5.117$

SMX $=4.311$

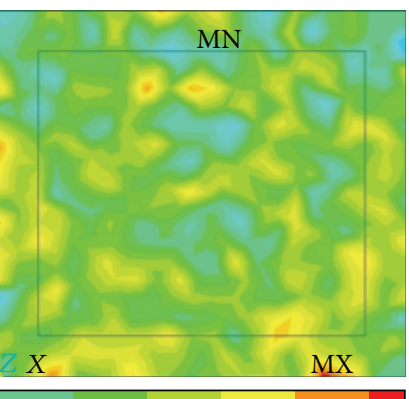

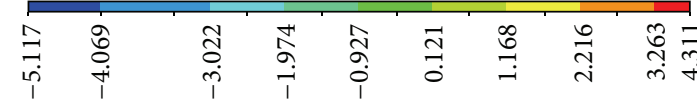

(h) $8000 \mathrm{~Hz}$

FIGURE 8: Sound pressure distributions for different frequencies at time $0.02567 \mathrm{sec}$. 
also analyzed. Table 1 lists the input data. To simplify the analysis model, the room length is assumed to exceed the width and height, simply considering the wave propagation of the central cross-section. The boundary thus is simply expressed as the boundaries of the width and height, with length being excluded. Two cases are studied for investigating the sound quality of indoor space. General characteristics of sound propagation at specified frequencies are analyzed in the first case. The rest shows the indoor sound quality evaluation for an electric fan and motor put into the space.

4.1. Characteristics of Indoor Sound Propagation. In this case, the analysis is unsuitable for the corners at the length direction. Figure 1 shows that the input frequency of sound pressure $1 \mathrm{kHz}$ and the induced length is five times that of the wavelength of the pulse wave under wave propagation at a distinct time. The ear-wave frequency response curve demonstrates that human ears respond differently to loudness at distinct frequencies. That is, human ears have different sensitivities to frequency, where the response to receiving the sound pressure $1 \mathrm{kHz}$ is consistent with the actual sound pressure. Consequently, $1 \mathrm{kHz}$ is used in the present analysis. The reason for the induced length being five times the wavelength may be that the length is considered the complete minimum pulse wave and thus that it is easier to identify the relevant physical parameters for the loudness competence. The setting computational duration for each step is $10^{-6} \mathrm{sec}$, where the sound pressure is distributed in tiny sections and the instant sound pressure diffusion is observable.

Figure 2 illustrates the wave propagation after the sound pressure is increased for $1 \times 10^{-6} \mathrm{sec}$ for the elements in the middle of the analysis. Figure 3 denotes the wave propagation for $1 \times 10^{-5} \mathrm{sec}$. When comparing with the Figure 2 , it is easy to understand the phenomenon of the sound wave propagating from top to bottom direction. Figure 4 shows the wave delivery for $0.0044 \mathrm{sec}$, where the wave reflection is visible on the left and right boundaries. Figure 5 illustrates the sound pressure distribution at time $0.05 \mathrm{sec}$, where the distribution of several reflected sound pressures in the room can be obtained when the sound pressure diffuses from the top and constantly reflects after passing the boundary. Figure 6 shows the sound pressure decay along the perpendicular direction of the sound source. It can be founded that higher sound decay exists at the far away sound source.

4.2. Indoor Sound Quality Evaluation for the Existence of an Electric Fan and Motor. When an indoor space existing a fluid machine, such as pump, fan, or air condition, the induced sound source for different frequency should be considered. For an electric fan and motor, the sound pressure of several frequencies is listed in Table 2 [14]. The corresponding sound distribution can be obtained using the ANSYS software. Figure 7 illustrates the pressure distribution at frequency $63 \mathrm{~Hz}$ when the sound propagates to the ground. The $0.008557 \mathrm{sec}$ travelling duration can be derived from the simulation process. Next, Figure 8 shows the pressure distribution of different frequencies $(63,125,250,500,1000,2000$, 4000 , and $8000 \mathrm{~Hz}$ ) at time $0.02567 \mathrm{sec}$. Since the frequency
TABLE 2: Sound pressure levels of an electric fan and motor.

\begin{tabular}{lcc}
\hline Frequency $(\mathrm{Hz})$ & Fan $(\mathrm{dB})$ & Motor $(\mathrm{dB})$ \\
\hline 63 & 84.6 & 49.0 \\
125 & 81.6 & 53.0 \\
250 & 83.6 & 57.0 \\
500 & 84.6 & 61.0 \\
1000 & 82.6 & 61.0 \\
2000 & 79.6 & 57.0 \\
4000 & 77.6 & 53.0 \\
8000 & 67.6 & 49.0 \\
\hline
\end{tabular}

varies at the same time, different pattern of distribution is represented.

The analysis data can be applied to evaluate the relevant physical parameters of the loudness component, including the interior sound quality analysis of the Reverberation Time required for the sound pressure at the fixed location attenuating to $60 \mathrm{~dB}$, with (1).

\section{Conclusion}

Using the frequency $1 \mathrm{kHz}$ and the induced time of five complete cycles of the pulse wave, this study analyzes the interior wave propagation. ANSYS analysis considers the boundary reflection, coupling, and the absorption characteristics of materials. The simulation results demonstrate the characteristics of interior wave propagation, as well as the superposition characteristics following boundary contact. The fluid machine sound source is also examined for obtaining the sound distribution of various amplitudes and frequencies. It can be further applied to the predesign analysis of interior architecture to improve interior noise and effectively reduce the construction costs and increase quality of life.

\section{References}

[1] S. B. Huang and J. P. Lai, "Research on noise limit of building boundary-noise of residential equipment," in Proceedings of the Annual Meeting and 15th Symposium of Acoustical Society of the Republic of China, Tainan, Taiwan, 2002.

[2] Y. Y. Hsieh, "Property analysis of air-conditioner noise in auditoriums in Taiwan," in Proceedings of the Annual Meeting and 16th Symposium of Acoustical Society of the Republic of China, pp. 238-242, Taipei, Taiwan, 2003.

[3] H. R. Hsieh, J. P. Lai, Y. Y. Hsieh, and T. R. Wu, "Investigation and analysis of current indoor noise in cultural centers," in Proceedings of the Annual Meeting and 13th Symposium of Acoustical Society of the Republic of China, Tainan, Taiwan, 2000.

[4] C. W. Chen and C. C. Chung, "Acoustic property of a newly built studio," in Proceedings of the Annual Meeting and 13th Symposium of Acoustical Society of the Republic of China, Tainan, Taiwan, 2000.

[5] W. H. Chiang, Y. K. Hsu, and C. C. Tsai, "Acoustic measurement of courtyard-type traditional Chinese theater," in Proceedings of the Annual Meeting and 16th Symposium of Acoustical Society of the Republic of China, pp. 279-284, Taipei, Taiwan, 2001. 
[6] S. H. Chang, H. W. Wu, and C. F. Hung, "A sound quality study of house hold electrical appliances by iury test in indoor space," The Open Acoustics Journal, vol. 6, pp. 11-19, 2013.

[7] M. Vorlander, "Computer simulations in room acoustics: concepts and uncertainties," Journal of the Acoustical Society of America, vol. 133, no. 3, pp. 1203-1213, 2013.

[8] X. F. Huang and Z. X. Yang, "Prediction of the sound pressure level in a small room," Applied Mechanicsand Materials, vol. 409-410, pp. 699-702, 2013.

[9] M. Aretz and M. Vorlander, "Combined wave and ray based room acoustic simulations of audio systems in car passenger compartments, part I: boundary and source data," Applied Acoustics, vol. 76, pp. 82-99, 2014.

[10] M. Aretz and M. Vorlander, "Combined wave and ray based room acoustic simulations of audio systems in car passenger compartments, part II: comparison of simulations and measurements," Applied Acoustics, vol. 76, pp. 52-65, 2014.

[11] K. C. Huang, Effects of interior decoration and sound source on sound field [M.S. dissertation], National Pingtung University of Science and Technology, Pingtung, Taiwan, 2008.

[12] T. Y. Liu and C. H. Li, "Calculation and experiment comparison of acoustic field clarity and reverberation time," in Proceedings of the Annual Meeting and 19th Symposium of Chinese Society of Sound and Vibration, 2006.

[13] "Environmental Protection Administration, Executive Yuan, Basic principles of noise and the control materials handbook".

[14] S.-Y. Hsia, S.-M. Chiu, and J.-W. Cheng, "Sound field analysis and simulation for fluid machines," Advances in Engineering Software, vol. 40, no. 1, pp. 15-22, 2009. 


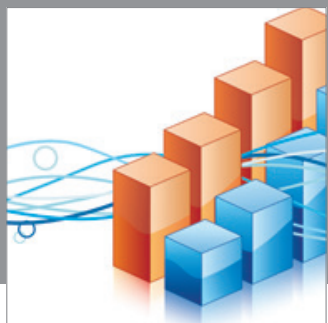

Advances in

Operations Research

mansans

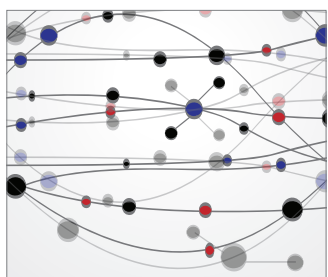

The Scientific World Journal
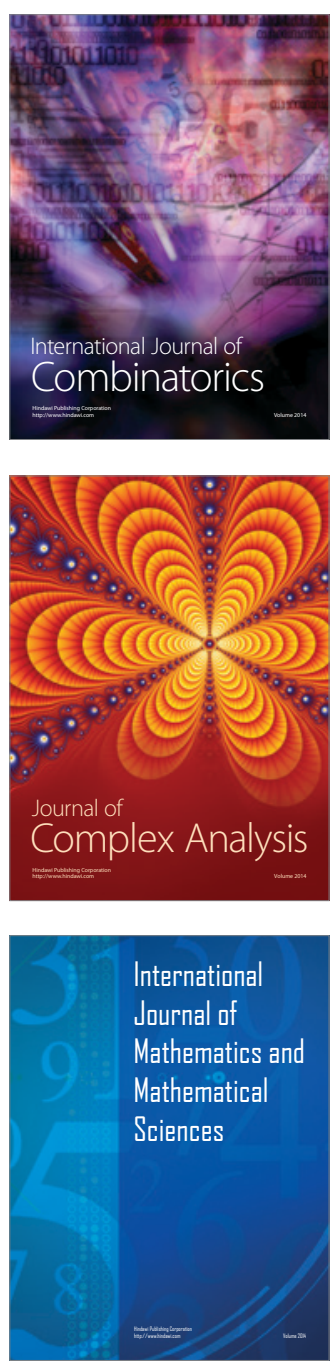
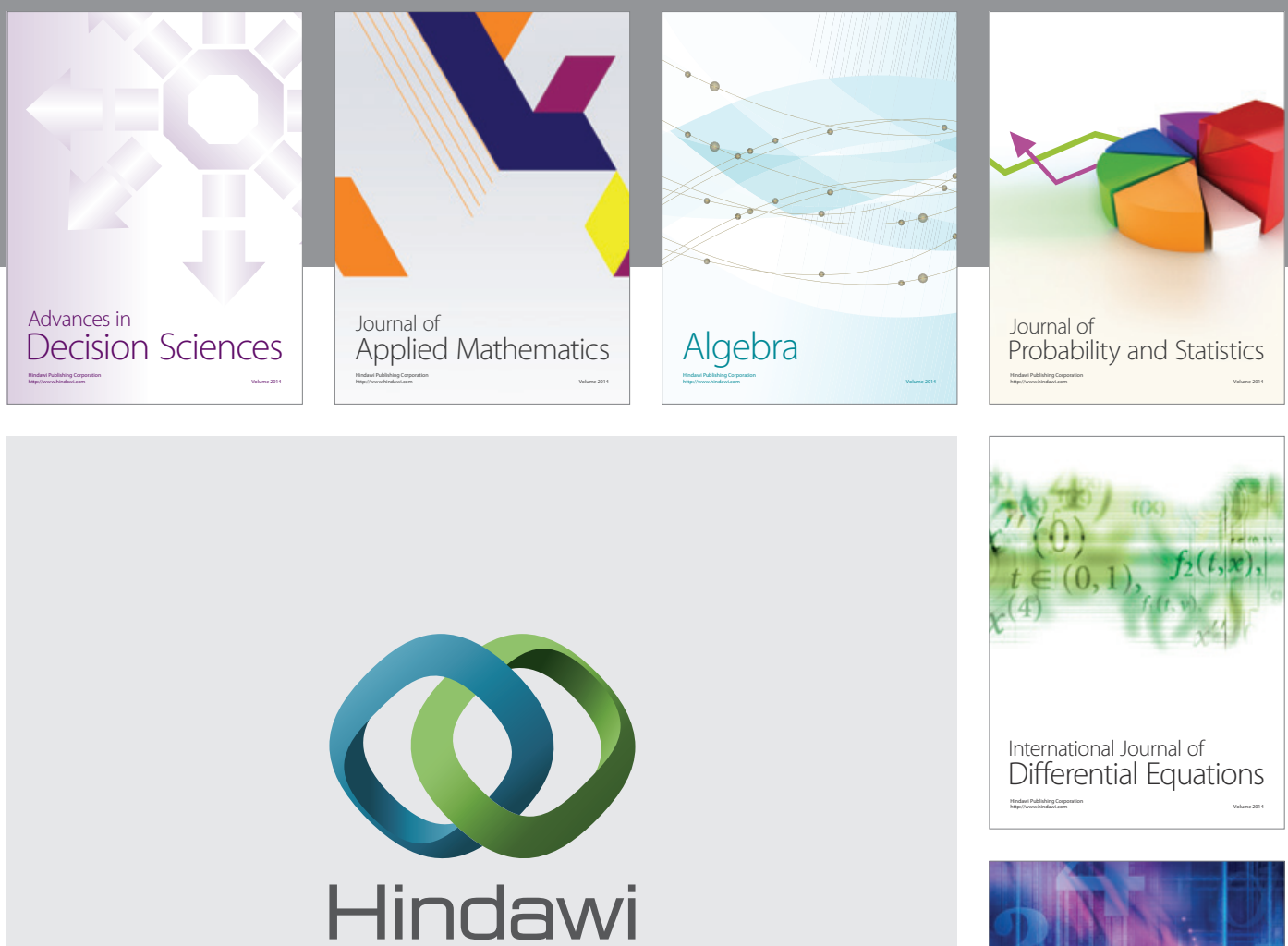

Submit your manuscripts at http://www.hindawi.com
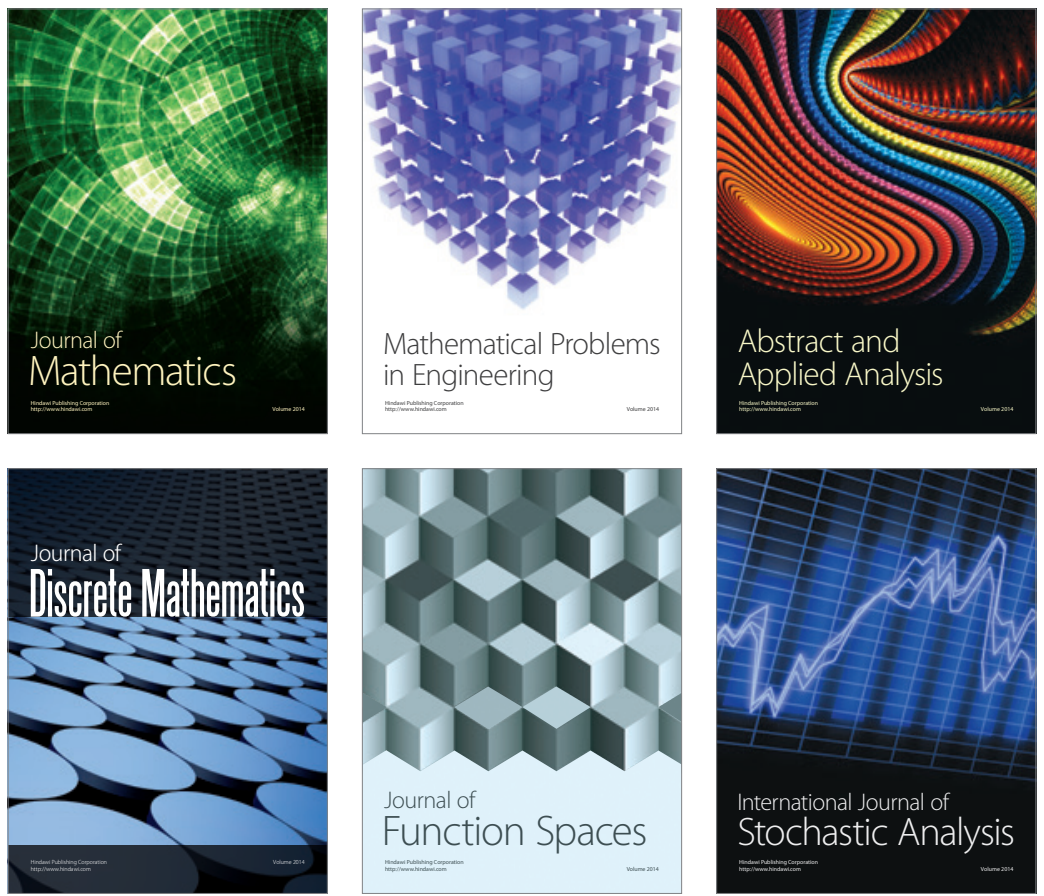

Journal of

Function Spaces

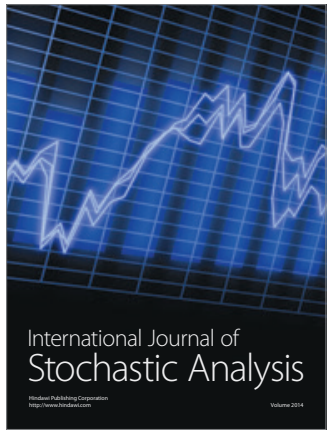

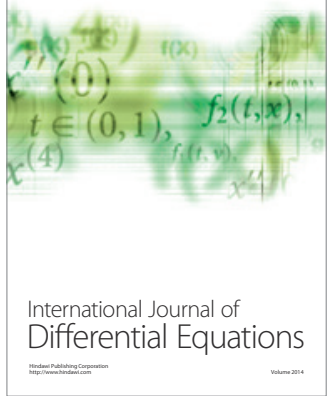
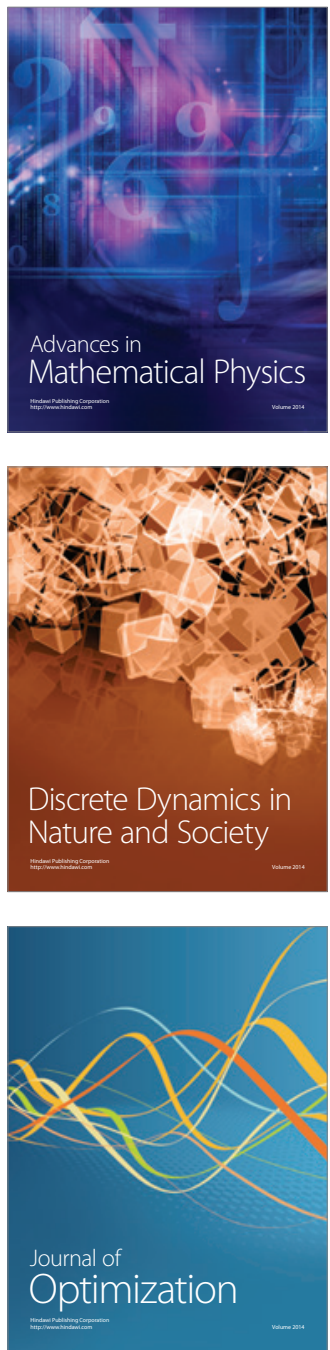